\title{
XPS AND ELECTRONIC STRUCTURE OF FERROELECTRIC $\mathrm{Sn}_{2} \mathrm{P}_{2} \mathrm{~S}_{6}$ CRYSTALS
}

\author{
J. Grigas ${ }^{\text {a }}$, E. Talik ${ }^{\text {b }, ~ V . ~ L a z a u s k a s ~}{ }^{\text {c }}$, Yu.M. Vysochanskii ${ }^{\text {d }}$, R. Yevych ${ }^{\mathrm{d}}$, \\ M. Adamiec ${ }^{\mathrm{b}}$, and V. Nelkinas ${ }^{\mathrm{c}}$ \\ ${ }^{a}$ Faculty of Physics, Vilnius University, Saulètekio 9, LT-10222 Vilnius, Lithuania \\ E-mail: jonas.grigas@ff.vu.lt \\ ${ }^{\mathrm{b}}$ Institute of Physics, Silesian University, Universytetska 4, 40-007 Katowice, Poland \\ ${ }^{\mathrm{c}}$ Institute of Theoretical Physics and Astronomy of Vilnius University, A. Goštauto 12, LT-01108 Vilnius, Lithuania \\ ${ }^{\mathrm{d}}$ Uzhgorod University, Pidhirna 46, UA-88000 Uzhgorod, Ukraine
}

Received 17 March 2008; revised 15 May 2008; accepted 9 June 2008

\begin{abstract}
Electronic properties of uniaxial ferroelectric $\mathrm{Sn}_{2} \mathrm{P}_{2} \mathrm{~S}_{6}$ single crystal are studied by X-ray photoelectron spectroscopy. X-ray photoelectron spectra (XPS) of the valence band (VB) and of the principal core levels (CL) are obtained from different crystallographic planes in both paraelectric and ferroelectric phases. The XPS were measured with monochromatized Al Ka radiation in the energy range $0-1400 \mathrm{eV}$. The VB consists of five bands with the maxima between 3.3 and $14.5 \mathrm{eV}$ below the Fermi level. Experimental energies of the VB and core levels are compared with results of theoretical ab initio calculations of molecular model of the $\mathrm{Sn}_{2} \mathrm{P}_{2} \mathrm{~S}_{6}$ crystal. Electronic structure of the VB is revealed. Ferroelectric phase transition changes atom's charge and bonds strength, VB electronic structure, CL lines width, and chemical shifts for the Sn, P, and S states which are crystallographic plane-dependent.
\end{abstract}

Keywords: $\mathrm{Sn}_{2} \mathrm{P}_{2} \mathrm{~S}_{6}$, ferroelectric, crystals, XPS, electronic structure

PACS: 71.20.-b, 77.84.-s, 78.70.En, 79.60.-i

\section{Introduction}

$\mathrm{X}$-ray photoelectron spectroscopy is widely used for investigations of the electronic structure of solids. Due to reduced co-ordination number, the surface atoms experience a different potential than the bulk atoms. Therefore, the core-electron binding energies are different for surface and bulk atoms. XPS enables one to study the surface valence changes, which affect the core-level shift with respect to the bulk atoms. Form and electronic structure of the VB and CL were studied both theoretically and experimentally in the quasi-onedimensional $\mathrm{Sb}_{2} \mathrm{~S}_{3}$ [1] and $\mathrm{Bi}_{2} \mathrm{~S}_{3}$ [2], SbSI [3], BiSI [4], and SbSeI [5] single crystals. XPS revealed huge crystallographic plane-dependent splitting of the core-level binding energies in ferroelectric SbSI, and smaller corelevel shifts in non-ferroelectric BiSI and SbSeI. Theoretical $a b$ initio calculations confirmed these findings. The valence band and core levels of these quasi-onedimensional crystals are extremely sensitive to changes of the chemical environment of atoms.

$\mathrm{Sn}_{2} \mathrm{P}_{2} \mathrm{~S}_{6}$ is a well-known uniaxial ferroelectric semiconductor, which exhibits a number of prominent strongly coupled semiconductive and ferroelectric properties that are discussed in detail in the monograph [6]. The room-temperature ferroelectric (FE) phase is a monoclinic one, with the space group Pc. Above $T_{\mathrm{c}}=$ $337 \mathrm{~K}$, the crystal undergoes a second-order ferroelectric phase transition into paraelectric (PE) monoclinic space group $\mathrm{P} 22_{1} / \mathrm{c}$. The shapes of the coordination polyhedrons of chalcogen atoms do not differ significantly. Below $T_{\mathrm{c}}$, all four $\mathrm{Sn}$ atoms are shifted significantly in the [100] direction, with respect to the locations in the centrosymmetric state. Two of them are shifted along the [010] direction by $0.04 \AA$, while the remaining two are shifted by the same distance along [010]. The two non-equivalent $\mathrm{Sn}$ atoms are shifted by $0.325 \AA$ along $a, 0.044 \AA$ along $b$, and $0.094 \AA$ along $c$ and by $0.225 \AA$ along $a, 0.044 \AA$ along $b$, and $0.033 \AA$ along $c$ direction, respectively. Two pairs of Sn atoms have different shifts in the FE phase. This is related to nonlinear interaction of soft $\mathrm{B}_{\mathrm{u}}$ and full symmetrical mode $\mathrm{A}_{\mathrm{g}}$ modes in the PE phase. This interaction is very important for the phase transition nature. Changes in the position of $\mathrm{P}$ and $\mathrm{S}$ atoms at $T_{\mathrm{c}}$ are small. Thus, 
Sn atoms shift mainly along the [100] direction and this allows considering the $\mathrm{Sn}$ sublattice as ferroactive.

Ferroelectricity in ferroelectric semiconductors is closely related to their electronic structure [7]. However, electronic properties of this crystal were less studied than structural and phonon properties [6]. Electronic structure of $\mathrm{Sn}_{2} \mathrm{P}_{2} \mathrm{~S}_{6}$ was studied by X-ray photoelectron and X-ray fluorescence spectroscopies in combination with the full-potential linearized augmented plane wave (FLAPW) band structure calculations only in ferroelectric phase [8]. Due to a relative complexity and low symmetry of the crystal, one can expect different XPS from the different crystal planes (as in SbSI [3]) as well as for the PE and FE phases. We failed to find any studies of the ferroelectric phase transition influence on the electronic structure of this crystal.

The purpose of this paper is to study XPS and electronic structure of the ferroelectric $\mathrm{Sn}_{2} \mathrm{P}_{2} \mathrm{~S}_{6}$ crystals in both FE and PE phases, and to reveal the influence of the ferroelectric phase transition on electronic structure of valence band and on shifts in core-level binding energies.

Organisation of the paper is as follows. A brief description of experimental details is given in Section 2. Section 3 presents a molecular model of the $\mathrm{Sn}_{2} \mathrm{P}_{2} \mathrm{~S}_{6}$ crystal and the Hartree-Fock-Roothan (HFR) method of $a b$ initio calculations of photoionization energies. The calculated bonds strength and atom's charge in the $\mathrm{PE}$ and FE phases as well as the calculated binding energies are presented and compared with the experimental findings. In Section 4, the results of calculated VB electronic structure and XPS of VB and CL for $\mathrm{Sn}_{2} \mathrm{P}_{2} \mathrm{~S}_{6}$ crystal from different crystallographic planes in the both - FE and PE - phases are presented. It is shown that the ferroelectric phase transition changes atom's charge and bonds strength, VB electronic structure, and CL lines width, as well as chemical shifts for the Sn, P, and S states, which are crystallographic plane-dependent. Finally, conclusions are given in Section 5 .

\section{Experimental details}

The $\mathrm{Sn}_{2} \mathrm{P}_{2} \mathrm{~S}_{6}$ crystal was grown by vapour transport. The crystal of good optical quality was $2 \mathrm{~cm}$ long and $1 \mathrm{~cm}^{2}$ in area. The XPS of valence band and principal core levels were measured using a PHI 5700/660 Physical Electronics spectrometer with monochromatic $\mathrm{Al} \mathrm{K} \mathrm{K}_{\alpha}$ radiation $(1486.6 \mathrm{eV})$ of $0.3 \mathrm{eV}$ full width at half maximum. The photoelectron spectra as functions of kinetic energy were analysed in the $0-1400 \mathrm{eV}$ energy
Table 1. Atomic concentration at different planes in FE (RT) and PE (360 K) phases.

\begin{tabular}{|c|c|c|c|c|c|c|}
\hline \multicolumn{7}{|c|}{ Atomic concentration } \\
\hline \multirow[t]{2}{*}{ Peak } & \multicolumn{2}{|c|}{$y z$ plane } & \multicolumn{2}{|c|}{$x y$ plane } & \multicolumn{2}{|c|}{$x z$ plane } \\
\hline & RT & $360 \mathrm{~K}$ & RT & $360 \mathrm{~K}$ & RT & $360 \mathrm{~K}$ \\
\hline P $2 p$ & 22.4 & 21.8 & 22.3 & 22.3 & 22.5 & 23.6 \\
\hline $\mathrm{S} 2 \mathrm{p}$ & 56.1 & 56.4 & 56.3 & 57.3 & 55.8 & 54.7 \\
\hline $\operatorname{Sn} 3 d^{5}$ & 21.5 & 21.8 & 21.4 & 20.4 & 21.7 & 21.7 \\
\hline
\end{tabular}

Table 2. Chemical composition at different planes in FE (RT) and PE (360 K) phases.

\begin{tabular}{ccccccccc}
\hline \multicolumn{9}{c}{ Chemical composition } \\
\hline \multirow{2}{*}{ Element } & \multicolumn{2}{c}{$y z$ plane } & & \multicolumn{2}{c}{$x y$ plane } & & \multicolumn{2}{c}{$x z$ plane } \\
\cline { 2 - 3 } & RT & $360 \mathrm{~K}$ & & RT & $360 \mathrm{~K}$ & & RT & $360 \mathrm{~K}$ \\
\hline $\mathrm{P}$ & 2.2 & 2.2 & & 2.2 & 2.2 & & 2.3 & 2.4 \\
$\mathrm{~S}$ & 5.6 & 5.6 & & 5.6 & 5.7 & & 5.6 & 5.5 \\
$\mathrm{Sn}$ & 2.2 & 2.2 & & 2.1 & 2.0 & & 2.2 & 2.2 \\
\hline
\end{tabular}

range by a hemispherical mirror analyzer. All spectra are obtained using $400 \mu$ m-diameter analysis area. The measurements were performed from the crystallographic planes perpendicular to ferroelectric $x$ axis, $z$ axis, and non-ferroelectric $y$ axis, cleaved in situ in the low $10^{-10}$ torr range vacuum to obtain the clean surfaces. The survey spectra taken directly after breaking the crystal showed small contamination by oxygen and a rather low one by carbon that should have no influence on the VB and CL spectra. The angle was $45^{\circ}$ between the sample and X-ray incident beam. A charging effect was observed. All spectra were corrected for this charging effect using the carbon 1s line of adsorbed carbon $\left(E_{\mathrm{b}}=285 \mathrm{eV}\right)$.

The most intensive core-level lines are selected to specify the stoichiometry of the crystal. The atomic concentration specified by the peak areas is shown in Table 1 . The experimentally determined atomic concentration is in good agreement with the ideal stoichiometry of the crystal. The chemical composition is given in Table 2. This indicates that the crystal has a high quality with regard to the chemical purity. However, the presented quantities slightly depend on the crystallographic plane and the phase.

\section{Molecular model of $\mathrm{Sn}_{2} \mathbf{P}_{2} \mathrm{~S}_{6}$ crystal and ab initio calculation of the energy levels}

The electronic structure of VB and CL was calculated by the method based on HFR equations solutions, in the Linear Combinations of Atomic Orbitals (LCAO) approach for the molecular orbitals (MO). According to 


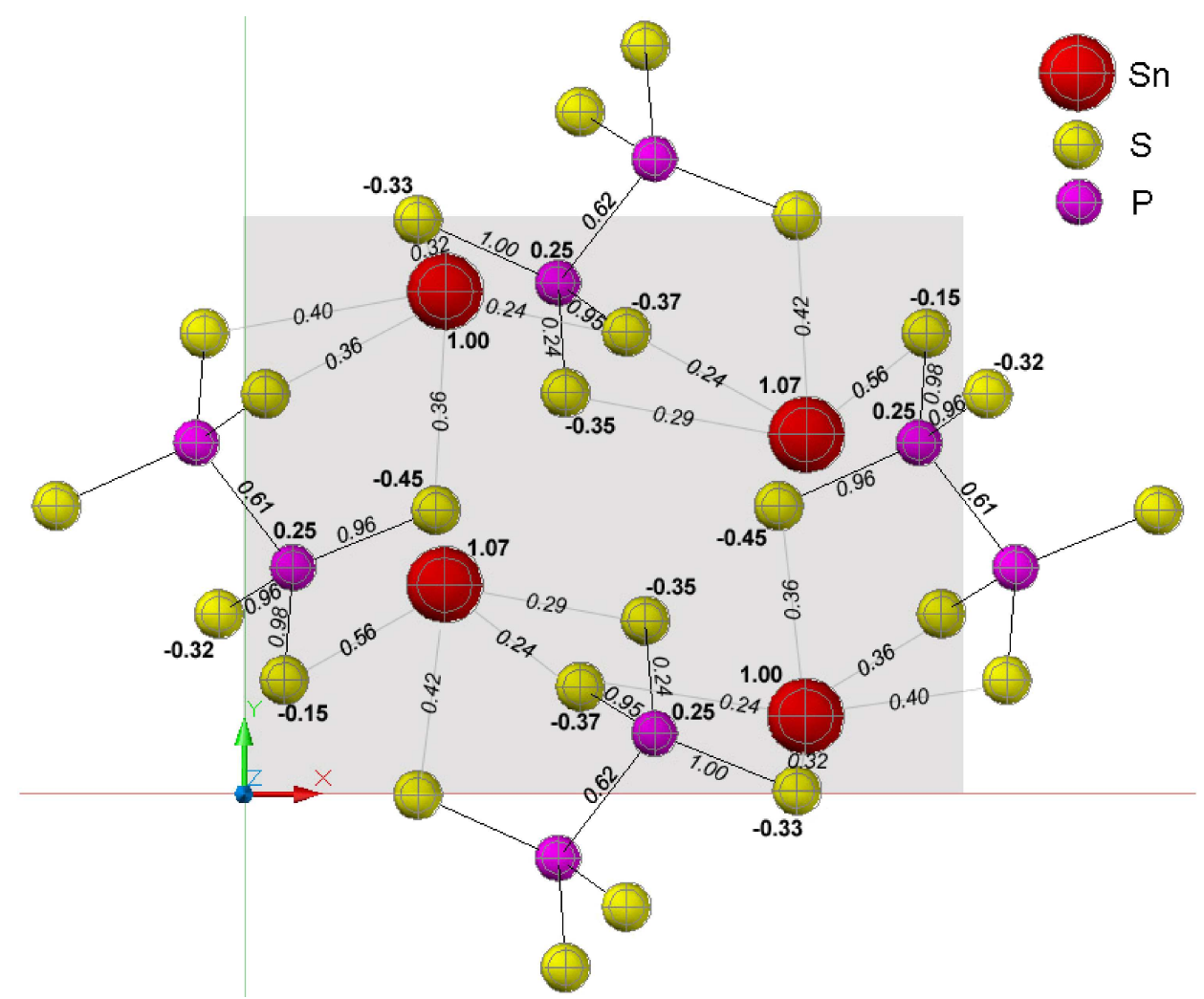

Fig. 1. $\mathrm{Sn}_{8}\left(\mathrm{P}_{2} \mathrm{~S}_{6}\right)_{8}$ cluster as a molecular model of $\mathrm{Sn}_{2} \mathrm{P}_{2} \mathrm{~S}_{6}$ crystal on the $x y$ plane. The calculated bond strengths and atom's charges in the PE phase are shown in the picture.

the Koopmans' theorem, the one-particle energies obtained from the canonical HFR equations correspond to the approximate ionization potentials. This would be an exact solution if the ionisation process were instantaneous and the correlation energy contribution could be completely neglected.

For calculating the energy levels we need a molecular model of the crystal. The model must be a cluster composed from an even number of molecules. However, the interaction between the clusters is not as weak as it should be. Figure 1 shows a fragment of the crystal structure on the $x y$ plane. The unit cell is shadowed. This selected $\mathrm{Sn}_{4}\left(\mathrm{P}_{2} \mathrm{~S}_{6}\right)_{4}$ cluster gives the stable HFR solution. Such a cluster was used for theoretical calculations.

The molecular orbital (MO) is a linear combination of atomic orbitals (AO). The MO $\left(\varphi_{i}\right)$ can be expanded in the $\mathrm{AO}\left(\chi_{\mu}(r)\right)$ basis:

$$
\varphi_{i}(\mathbf{r})=\sum_{\mu=1}^{M} C_{i \mu} \chi_{\mu}(\mathbf{r}),
$$

where $\mu$ is the number of the $\mathrm{AO}$, or the set of quantum numbers $n l m$. For simplicity, a Gaussian 3G orbital ba- sis set [9] is used. The $\mathbf{C}$ matrix is obtained by solving Hartree-Fock matrix equation

$$
\mathbf{F C}=\mathbf{S C} \boldsymbol{\varepsilon} .
$$

Equation (2) is solved by diagonalization as described in [1-3]. As the matrix $\mathbf{F}$ nonlinearly depends on unknown coefficients $C_{i \mu}$, the Eq. (2) is solved by iterations method. The diagonal matrix $\varepsilon$ gives the energies of MO levels. For the core levels they nearly correspond to the energy of the AO levels. However, due to interaction they are slightly diffused. Method of finding the overlap integrals $S_{\mu \nu}$ and the Fock's matrix (F) elements is also described in [1-3].

The coefficients $C_{i \mu}$ allow us to calculate the electronic structure of molecules and to interpret the experimental results. They also allow us to find the matrix of the electron distribution density, according to Mullicken, which is given by

$$
P_{\mu \nu}=2 \sum_{i=1}^{N / 2} C_{i \mu} C_{i \nu}
$$

Here $N$ is the number of electrons. For the closed shells $N$ is even. 
Table 3. Sn-S bonds strength in FE and PE phases. Numbers of atoms are given in Fig. 1.

\begin{tabular}{|c|c|c|c|c|c|c|c|c|c|c|c|}
\hline Sn $1-S$ & FE & PE & $\mathrm{Sn} 2-\mathrm{S}$ & FE & PE & Sn3-S & FE & PE & Sn4-S & $\mathrm{FE}$ & PE \\
\hline $1-9$ & 04 & 05 & 11 & 055 & 040 & 31 & & 02 & & 0.23 & 0.36 \\
\hline & & & & & 0 & & & & & & 36 \\
\hline $1-$ & 0.42 & 0 & & 0 & 0.36 & & & .29 & & 32 & .40 \\
\hline $1-3$ & 0.38 & 0.24 & & 0.36 & 0.32 & & 0.07 & 0.24 & & 0.46 & 0.24 \\
\hline $1-35$ & 0.43 & 0.29 & $2-33$ & 0.10 & 0.24 & 3-32 & 0.28 & 0.42 & $4-29$ & 0.33 & 0.32 \\
\hline
\end{tabular}

The bond strengths $P_{\mathrm{AB}}$ between the atoms $\mathrm{A}$ and $\mathrm{B}$

$$
P_{\mathrm{AB}}=\sum_{\mu \in \mathrm{A}} \sum_{\nu \in \mathrm{B}} P_{\mu \nu}
$$

and the charge of the atoms is given by

$$
q_{\mathrm{A}}=Z_{\mathrm{A}}-\sum_{\mu \in \mathrm{A}} P_{\mu \mu} .
$$

This method of calculations is implemented in GAMESS program [10], which can deal with the molecular clusters up to $M \leq 2000$ orbitals or 250 atoms in MINI base. MIDI base is twice bigger for valence electrons and better describes the VB. We used both MINI and MIDI $3 \mathrm{G}$ orbital basis sets. The calculations are done using the experimental lattice parameters [6]. The calculated bond strengths and the Mullicken charge of the atoms in the PE phase are shown in Fig. 1. In this model, Sn atom's charge is close to +1 and the crystal is ionic $\operatorname{Sn}_{2}^{+}\left(\mathrm{P}_{2} \mathrm{~S}_{6}\right)^{-}$. At the FE phase transition, the bonds strength and charge of atoms change. The greatest changes occur in Sn3 surroundings. These changes are given in Table 3 . Those results show that a rear- rangement of most of the bonds takes place at the ferroelectric phase transition. The valence of ferroactive Sn ions also changes: $\mathrm{Sn} 1$ is 3.03 and $2.99, \mathrm{Sn} 2$ is 2.81 and 2.72, $\mathrm{Sn} 3$ is 1.92 and 2.99, and $\mathrm{Sn} 4$ is 2.81 and 2.72 in the PE and FE phase, respectively. The valence and charge of $\mathrm{Sn} 3$ ions change at phase transition most of all, i. e. they decrease in the FE phase (charge decreases from 1.07 to 0.95 ).

However, the cluster $\mathrm{Sn}_{4}\left(\mathrm{P}_{2} \mathrm{~S}_{6}\right)_{4}$ obviously does not reflect the symmetry of $\mathrm{Sn}_{2} \mathrm{P}_{2} \mathrm{~S}_{6}$ crystal unit cell, which contains two formula units $-\mathrm{Sn}_{4}\left(\mathrm{P}_{2} \mathrm{~S}_{6}\right)_{2}$. This determines different charges of $\mathrm{Sn} 1$ and $\mathrm{Sn} 3$ ions in the paraelectric phase.

Table 4 presents theoretical values of binding energies of the $\mathrm{Sn}_{4}\left(\mathrm{P}_{2} \mathrm{~S}_{6}\right)_{4}$ cluster without taking into account the spin-orbit interaction. The quantum mechanical method and the chosen cluster give higher negative CL as well as VB energies than their experimental values are (see Table 5). Nevertheless, the cluster reflects the electronic structure and binding energies of the crystal.

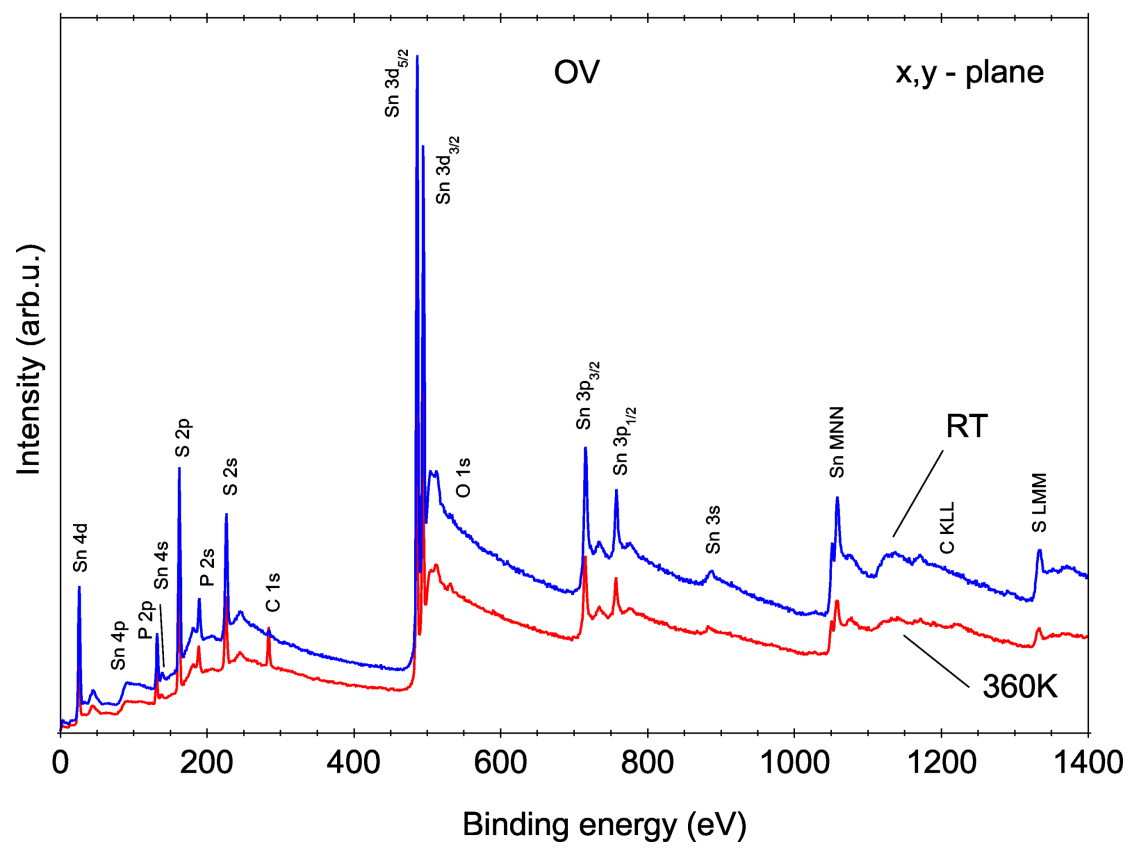

Fig. 2. Overview spectra of $\mathrm{Sn}_{2} \mathrm{P}_{2} \mathrm{~S}_{6}$ crystal from the $x y$ plane in the PE (360 K) and FE (RT) phases. 
Table 4. Values of the calculated binding (negative) energies $(\mathrm{eV})$.

\begin{tabular}{ccc}
\hline State & FE phase & PE phase \\
\hline Sn 3s & $860.7-859.7$ & $860.3-860.2$ \\
Sn 3p & $741.2-740.1$ & $740.8-740.7$ \\
Sn 3d & $520.2-519.1$ & $519.8-519.7$ \\
S 2s & $246.3-240.1$ & $244.9-241.4$ \\
P 2s & $210.1-207.9$ & $209.5-208.8$ \\
S 2p & $182.3-175.9$ & $180.8-177.2$ \\
P 2p & 153.1 & 152.7 \\
Sn 4s & 149.7 & 150.6 \\
Sn 4p & $111.2-110.1$ & 110.7 \\
Sn 4d & $40.5-39.4$ & $40.1-39.9$ \\
\hline
\end{tabular}

\section{Results of XPS and electronic structure}

\subsection{Survey spectra}

Figure 2 shows the XPS of the $\mathrm{Sn}_{2} \mathrm{P}_{2} \mathrm{~S}_{6}$ crystal in the energy range from 0 to $1400 \mathrm{eV}$ below the Fermi level in the both, PE $(360 \mathrm{~K})$ and FE (RT), phases from the crystallographic $x y$ plane. Only small amounts of oxygen $(\mathrm{O} 1 \mathrm{~s})$ and carbon $(\mathrm{C} 1 \mathrm{~s})$ have been detected. The spectra from other crystallographic planes are similar. However, CL peaks in the ferroelectric phase are higher. Inelastically scattered electrons give the background. Auger spectra of Sn MNN, S LMM, and C KLL are also seen in the high energy range. The strongest peaks of Sn 3d, Sn 4d, Sn 3p, P 2p, S 2p were cho-

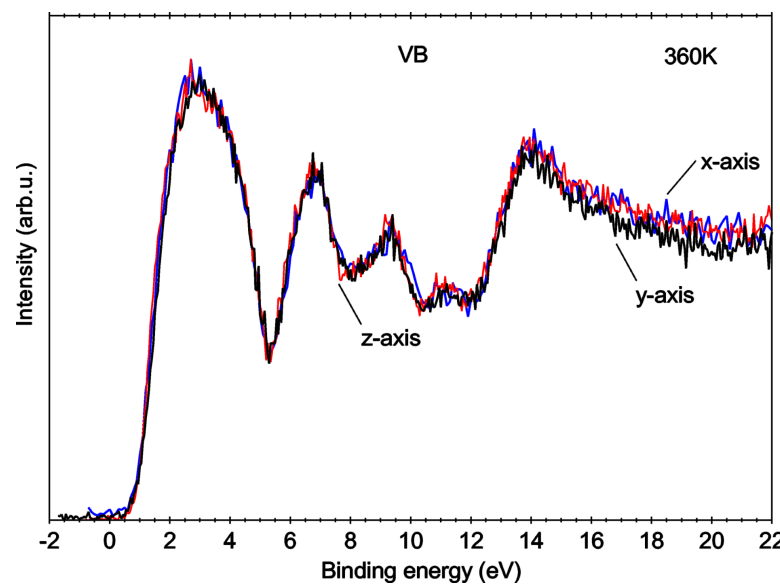

Fig. 3. XPS of VB in the PE phase from the crystallographic planes perpendicular to all the three axes.

sen for investigation of peculiarities of the crystallographic plane-dependent core-level XPS in this ferroelectric semiconductor.

\subsection{Valence band}

X-ray photoelectron spectroscopy of the valence band provides data on the occupied total density of states. Figure 3 shows the VB spectra in the PE phase from the crystallographic planes perpendicular to all three axes. The VB consists of five distinguishable bands with the maximum intensity at 2.8, 6.7, 9.2, 11.0,

Table 5. Binding energies and chemical shifts of atoms at different planes in FE (RT) and PE (360 K) phases.

\begin{tabular}{|c|c|c|c|c|c|c|}
\hline \multicolumn{7}{|c|}{ Binding energy $(\mathrm{eV})$} \\
\hline \multirow[t]{2}{*}{ Peak } & \multicolumn{2}{|c|}{$y z$ plane } & \multicolumn{2}{|c|}{$x y$ plane } & \multicolumn{2}{|c|}{$x z$ plane } \\
\hline & RT & $360 \mathrm{~K}$ & RT & $360 \mathrm{~K}$ & RT & $360 \mathrm{~K}$ \\
\hline $\begin{array}{l}\mathrm{P} 2 \mathrm{p}_{3 / 2} \text { in compound } \\
\mathrm{P} 2 \mathrm{p}_{3 / 2} \text { in literature }\end{array}$ & 132.0 & 131.8 & $\begin{array}{r}132.6 \\
13\end{array}$ & $\begin{array}{l}132.1 \\
.0\end{array}$ & 132.3 & 131.8 \\
\hline chemical shift & 2.0 & 1.8 & 2.6 & 2.1 & 2.3 & 1.8 \\
\hline $\begin{array}{l}\mathrm{P} 2 \mathrm{p}_{1 / 2} \text { in compound } \\
\mathrm{P} 2 \mathrm{p}_{3 / 2} \text { in literature }\end{array}$ & 132.9 & 132.6 & $\begin{array}{r}133.5 \\
13\end{array}$ & $\begin{array}{l}133.0 \\
.0\end{array}$ & 133.2 & 132.6 \\
\hline chemical shift & 1.9 & 1.6 & 2.5 & 2.0 & 2.2 & 1.6 \\
\hline $\begin{array}{l}\mathrm{S} 2 \mathrm{p}_{3 / 2} \text { in compound } \\
\mathrm{S} 2 \mathrm{p}_{3 / 2} \text { in literature }\end{array}$ & 162.3 & 161.9 & $\begin{array}{r}162.7 \\
16\end{array}$ & 162.3 & 162.4 & 161.7 \\
\hline chemical shift & -1.7 & -2.1 & -1.3 & -1.7 & -1.6 & -2.3 \\
\hline $\begin{array}{l}\mathrm{S} 2 \mathrm{p}_{1 / 2} \text { in compound } \\
\mathrm{S} 2 \mathrm{p}_{3 / 2} \text { in literature }\end{array}$ & 163.5 & 163.0 & $\begin{array}{r}163.9 \\
16\end{array}$ & 163.5 & 163.6 & 162.9 \\
\hline chemical shift & -1.5 & -2.0 & -1.1 & -1.5 & -1.4 & -2.1 \\
\hline $\begin{array}{l}\text { Sn } 3 d_{5 / 2} \text { in compound } \\
\text { Sn } 3 d_{5 / 2} \text { in literature }\end{array}$ & 486.7 & \multicolumn{4}{|c|}{485.0} & 486.3 \\
\hline chemical shift & 1.7 & 1.5 & 1.9 & 1.3 & 1.8 & 1.3 \\
\hline $\begin{array}{l}\text { Sn } 3 d_{3 / 2} \text { in compound } \\
\text { Sn } 3 d_{3 / 2} \text { in literature }\end{array}$ & \multicolumn{6}{|c|}{493.0} \\
\hline chemical shift & 2.1 & 1.9 & 2.3 & 1.7 & 2.5 & 1.6 \\
\hline
\end{tabular}




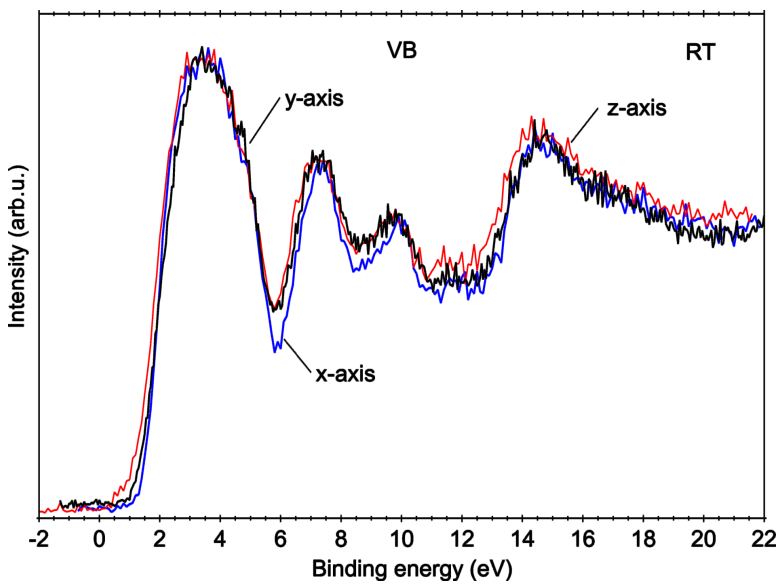

Fig. 4. XPS of VB in the FE phase from the three crystallographic planes.

and $14.0 \mathrm{eV}$. The similar but more outspread bands are in the FE phase (Fig. 4). Their energies are shifted by approximately $0.5 \mathrm{eV}$ to higher values and coincide with those obtained in [6]. The $11.0 \mathrm{eV}$ band in this phase is nearly erased. In the PE phase, the VB is separated by a gap of about $1.1 \mathrm{eV}$ from the Fermi level. In the ferroelectric RT phase, the VB is located at about 1.5 to $22 \mathrm{eV}$ below $E_{\mathrm{F}}$. In these crystals, the optical band gap at room temperature is $2.3 \mathrm{eV}$. It means that the Fermi level is pinned nearly in the middle of the band gap.

Figure 5 shows the calculated PE phase VB form and electronic structure of $\mathrm{Sn}_{2} \mathrm{P}_{2} \mathrm{~S}_{6}$ crystal. The spectrum is referred to the Fermi level $E_{\mathrm{F}}$. The $E_{\mathrm{F}}$ was determined experimentally within the accuracy of $0.3 \mathrm{eV}$. The intensities of the XPS were described:

(a) by the energy states band $\varepsilon_{i}$ from the characteristic Eq. (2);

(b) by the peaks of the density of states:

$$
D(\varepsilon)=\frac{1}{N_{\mathrm{M}}} \frac{1}{\Delta \varepsilon},
$$

where $N_{\mathrm{M}}$ is the number of molecules in the cluster;

(c) by the Gaussian broadening [11]:

$$
D(\varepsilon)=\frac{1}{\sqrt{2 \pi \sigma}} \sum_{i} \exp \left[-\frac{\left(\varepsilon-\varepsilon_{i}\right)^{2}}{2 \sigma^{2}}\right]
$$

where the summation is performed over the states $i$, $\varepsilon_{i}$ are the corresponding energy levels, and $\sigma$ is the half-width of the Gaussian function.

The Gaussian broadening method is the simplest approach to the Brillouin-zone spectral integrations. The $k$-points are distributed as evenly as possible throughout the Brillouin zone, and the DOS $D(\varepsilon)$ is formed ac-
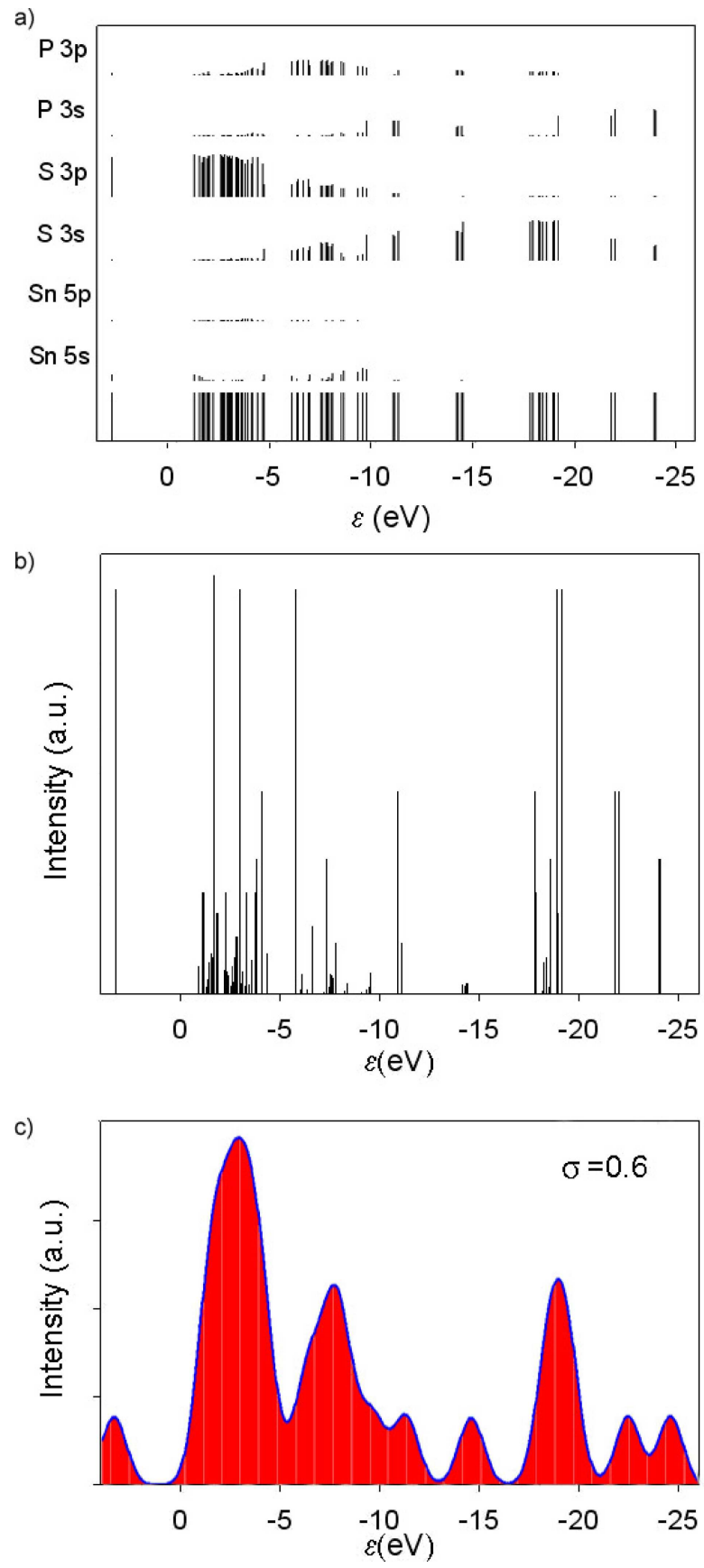

Fig. 5. Electronic structure of VB in PE phase: (a) DOS band and contribution of states (\%); (b) intensity of DOS ( $\Delta \varepsilon=0.27 \mathrm{eV}$ taken in Eq. (6)); (c) calculated VB for $\mathrm{Sn}_{4}\left(\mathrm{P}_{2} \mathrm{~S}_{6}\right)_{4}$ cluster and approximated by the Gaussian broadening method (Eq. (7)).

cording to Eq. (6). This method is designed for efficient calculation of experimentally observed crystal spectral properties where experimental and lifetime broadenings place a limit on the resolution required.

Further, all experiments have a finite energy resolution and frequently concentrate on the shifts, distortions, and changes in weight in the spectral features. In the approach used (Eq. (7)), the aim was to calcu- 
late the DOS only at the high density of $k$-points and then to smear the resulting spectrum to the experimental resolution. However, the application of the Gaussian smearing to the DOS results in good convergence at low $k$-point sampling densities.

The form of the VB can be explained by the analysis of MO population. Knowing the MO coefficients $C_{i \mu}$ (Eq. (1)), we can evaluate the contribution of the A atom electrons to $\varepsilon_{i}$ state:

$$
p_{i \mathrm{~A}}=\sum_{\mu \in \mathrm{A}} C_{i \mu}^{2} .
$$

From the partial density of states (PDOS) (in \%) calculated by Eq. (8) and the total density of states (a), the representation $D(\varepsilon)$ for the peaks (b) of the DOS (Eq. (6)), and approximation of the bands spectra (c) by the Gaussian broadening method (Eq. (7)) for $\mathrm{Sn}_{4}\left(\mathrm{P}_{2} \mathrm{~S}_{6}\right)_{4}$ molecular cluster (Fig. 5) it follows that from 4 to $2 \mathrm{eV}$ there is a conduction band (CB), the right edge of which is formed by $\mathrm{S} 3 \mathrm{p}$ electrons. Unlike $\mathrm{Sb}_{2} \mathrm{~S}_{3}$-type [1,2] and SbSI-type [3-5] crystals, the VB consists of five bands. It is dominated by $\mathrm{Sn} 5 \mathrm{~s}, \mathrm{Sn}$ 5 p, S 3s, S 3p, P 3s, and P 3p states. Five DOS peaks are degenerate. The main contribution to the most intensive band between -1 and $-5 \mathrm{eV}$ is given by $\mathrm{S} 3 \mathrm{p}$ states. The left edge of this band is formed by $\mathrm{S} 3 \mathrm{p}$ states with $13 \% \mathrm{Sn} 5 \mathrm{~s}$ and few percent $\mathrm{P} 3 \mathrm{p}$ states. The main contribution to the next intensive band between -5 and $-12 \mathrm{eV}$ comes from S 3s, S 3p, P 3p, and Sn $5 \mathrm{~s}$ states. Sn $5 \mathrm{~s}$ and $5 \mathrm{p}$ states give only small contribution to the first two bands. The low-energy part of VB is formed mainly by S $3 \mathrm{~s}$ and P $3 \mathrm{~s}$ states. S 3s electrons form band at $-14 \mathrm{eV}$, while $\mathrm{P} 3 \mathrm{~s}$ electrons form band at $-18.5 \mathrm{eV}$. Above $-25 \mathrm{eV}$ dominate $\mathrm{P} 3 \mathrm{~s}$ with mixture of $\mathrm{S} 3 \mathrm{~s}$ states. The five experimental bands at $-3.3,-7.2,-9.7,-11.5$, and $-14.5 \mathrm{eV}$ are in good agreement with [8].

The calculated bands are shifted to higher energies, however. It means that electron-electron interactions are overestimated. CL electrons extend the VB to higher energies. This is also confirmed experimentally. Higher-energy edges of all the bands are more outspread (Figs. 3, 4). The last three high-energy bands experimentally are seen as one diffused band. Tin atoms are strongly ionized. The electron density from Sn goes primarily to the neighbouring $\mathrm{S}$ atoms, yielding nearly full occupation of the S 3p band. The calculated PDOS in this approach differs slightly from the FLAPW calculations [8]; however, the main VB features are the same. Intensity of DOS is higher and minima are deeper than in FE phase. Due to the quasi-degenerate levels, the
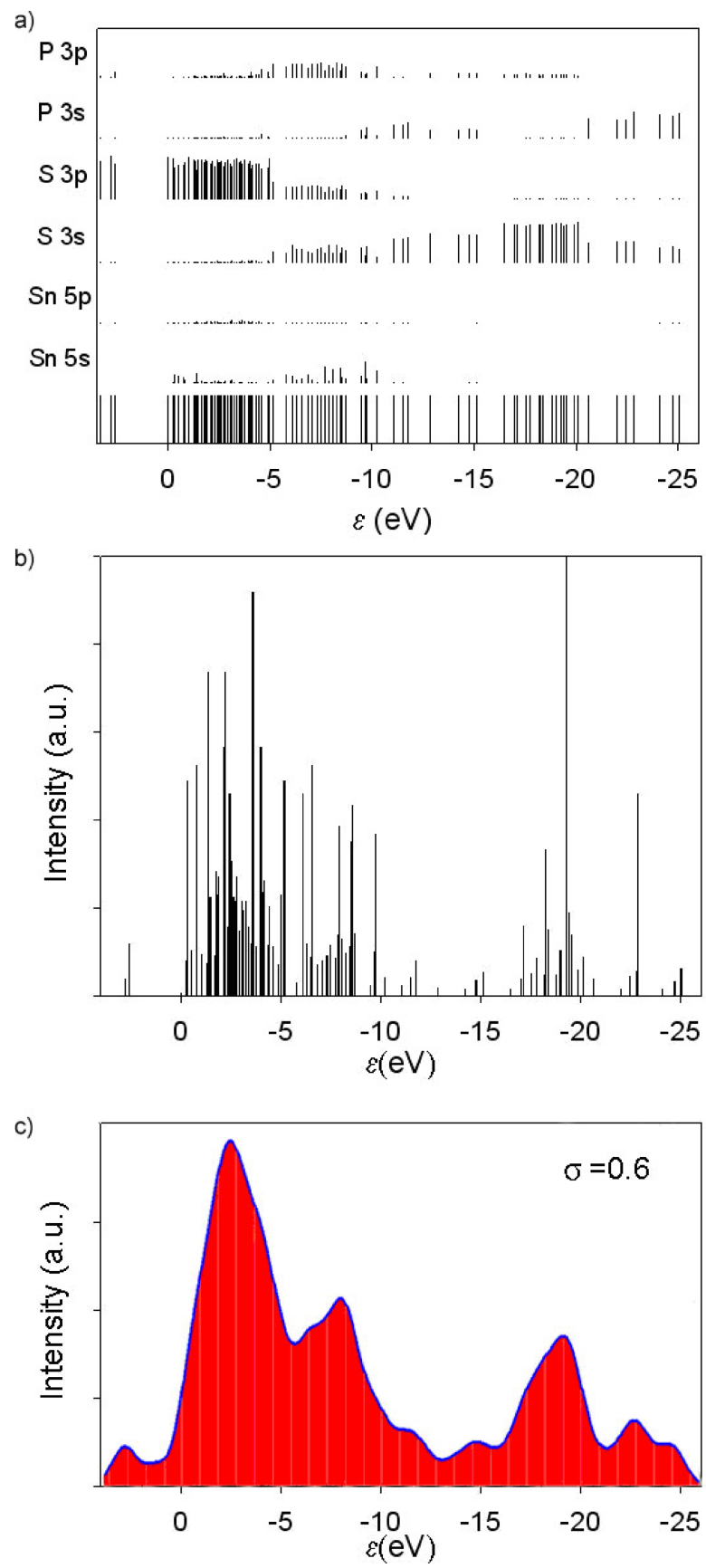

Fig. 6. Electronic structure of VB in FE phase. Designations are the same as in Fig. 5. $\Delta \varepsilon=0.021 \mathrm{eV}$ taken in Eq. (6), therefore the intensities are lower and minima are shallower than in PE phase.

PE phase DOS band is rarefied in comparison with FE phase DOS.

Figure 6 shows the calculated VB form and electronic structure of FE phase. The gap between the VB and $\mathrm{CB}$ decreases from $4.1 \mathrm{eV}$ (in PE phase) to $2.6 \mathrm{eV}$. The calculated width of the VB is $24.9 \mathrm{eV}$, while in PE phase it is $23.1 \mathrm{eV}$. In FE phase, there is only one quasidegenerate state instead of five in PE phase. Disappearance of centro-symmetry lifts degeneracy of the elec- 
tronic states. The left edge of the most intensive band between -1 and $-5 \mathrm{eV}$ is formed by $\mathrm{S} 3 \mathrm{p}$ states with few percent of P 3p states. Sn 5s states disappear. The phase transition does not change essentially the electronic structure of the crystal.

Mechanism of the tin cations electron lone pair formation, which is related to the appearance of the spontaneous polarization [12], could be used for explaining the VB spectra evolution at transition from the PE phase to FE one. The hybridization of $\mathrm{sp}^{2}$ type determines peculiarities of the density of states in VB. Antibonding mixing of $S n 5 s-S 3 p$ orbitals gives states at the top of VB. Bonding interaction of Sn $5 p$ orbitals with previous antibonding $\mathrm{Sn} 5 \mathrm{~s}-\mathrm{S} 3 \mathrm{p}$ states generates lower-energy filled states $\operatorname{Sn} 5 p+(\operatorname{Sn} 5 s-S 3 p), s^{2}$ for short. By this the gain of electronic subsystem energy is determined. Lowering of these $\mathrm{sp}^{2}$ states energy is proportional to acentricity of the Sn ions surrounding (similarly to the known Jahn-Teller effect). Such formation of the Sn lone pair electron "cloud" together with deformation of nearest sulphur atoms polyhedron determine the origin of spontaneous polarization. So, at transition to the FE phase and increase of spontaneous polarization the discussed $\mathrm{sp}^{2}$ hybridization becomes stronger and by this the density of electronic states at top of the VB is lowered. The observed lowering of energy of the band with maximum near $3 \mathrm{eV}$ in the VB XPS on cooling from $360 \mathrm{~K}$ to RT could be interpreted in such manner.

\subsection{Core levels}

Figures 7-9 show the spectra of Sn $3 d$, Sn $4 d$, and $\mathrm{S} 2 \mathrm{p}$ spin-orbit doublets from the $x y$ plane in the FE and PE phases. In the FE phase, all the CL bands are broader than in the PE phase. This indicates stronger interactions and higher bond strengths. However, even in the PE phase the peak width, i.e. the interaction, is also crystallographic plane-dependent (Fig. 10). The strongest interactions are observed for the polar $y z$ plane.

Sn $3 \mathrm{~d}$ and $4 \mathrm{~d}$ spectra could be described by two lines in PE phase. Indeed, in PE phase all Sn ions are equivalent. In FE phase, two non-equivalent pairs of $\mathrm{Sn}$ ions already exist.

Sn $4 \mathrm{~d}$ spectral lines in PE phase could be described by two Voight contours with $1.04 \mathrm{eV}$ splitting and 1.02$0.85 \mathrm{eV}$ width. Such spectra obviously are related to four equivalent $\mathrm{Sn}$ atoms. In the $\mathrm{FE}$ phase, the spectra are best fitted by three doublets with near to $1.04 \mathrm{eV}$ splitting. One doublet is placed at energy position similar to observed for doublet in the PE phase. Another two

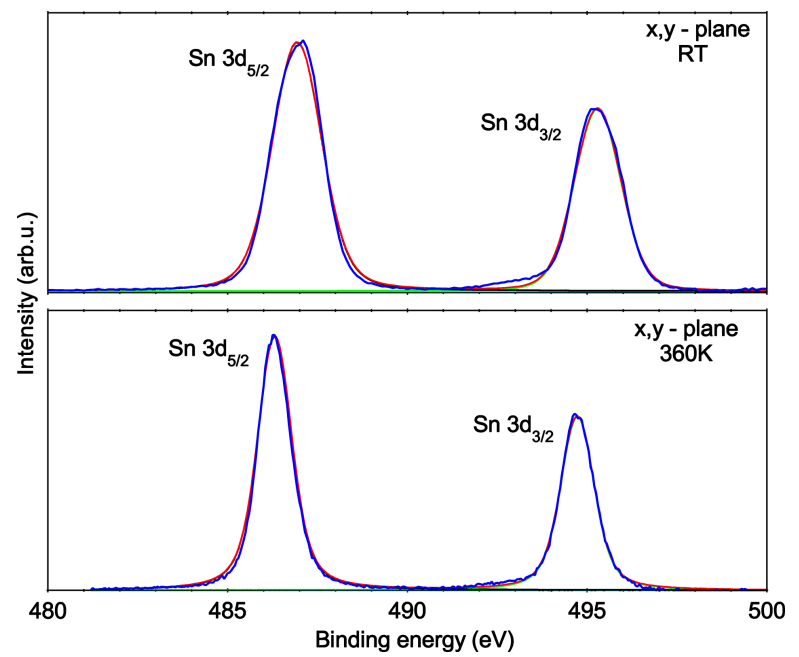

Fig. 7. XPS of Sn 3d spin-orbit doublet in FE (RT) and PE (360 K) phases.
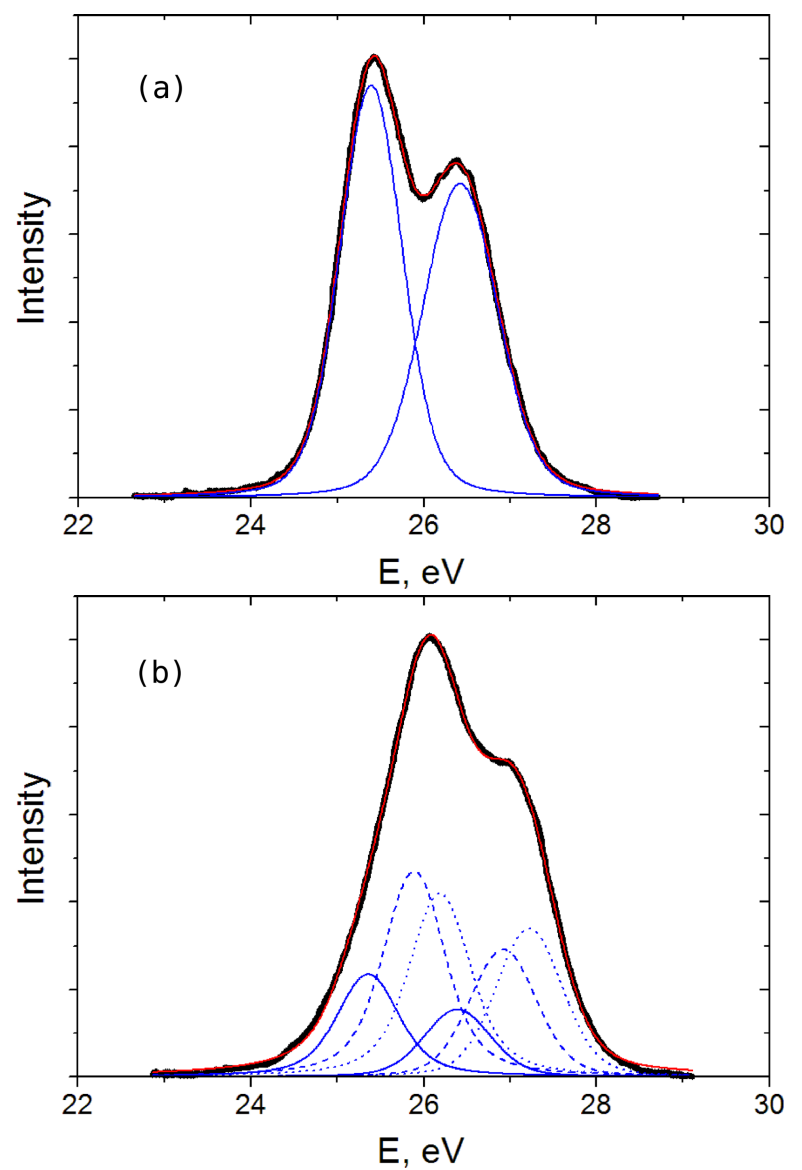

Fig. 8. XPS (in arb. units) of Sn 4d spin-orbit doublet in (a) PE and (b) FE phases.

doublets are shifted to higher energies. Line width is smaller $(0.85-0.91 \mathrm{eV})$ than that found in the PE phase. Such spectra could be explained taking into account the triple-well potential energy surface for $\mathrm{Sn}_{2} \mathrm{P}_{2} \mathrm{~S}_{6}$ ferroelectrics [12]. This lowest energy doublet could be re- 


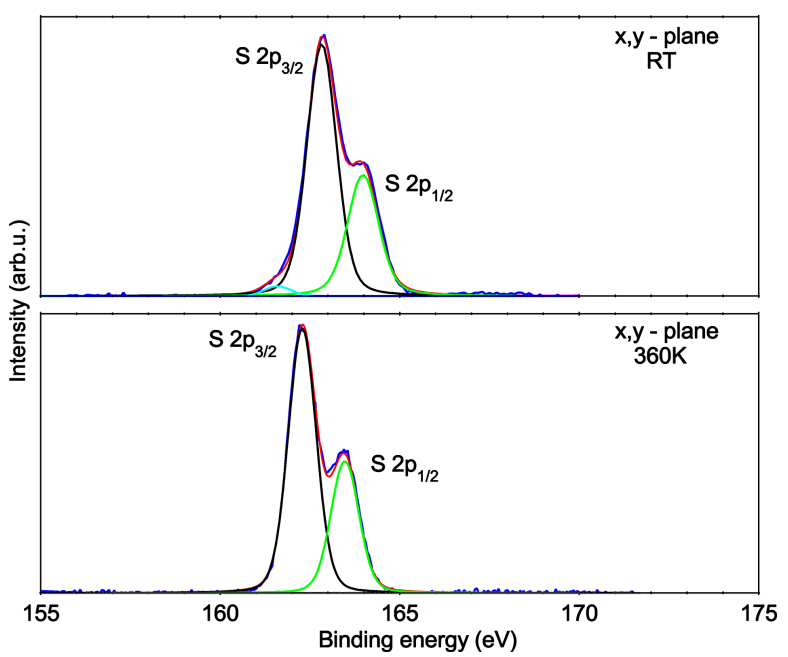

Fig. 9. XPS of S 2p spin-orbit doublet in FE (RT) and PE (360 K) phases.

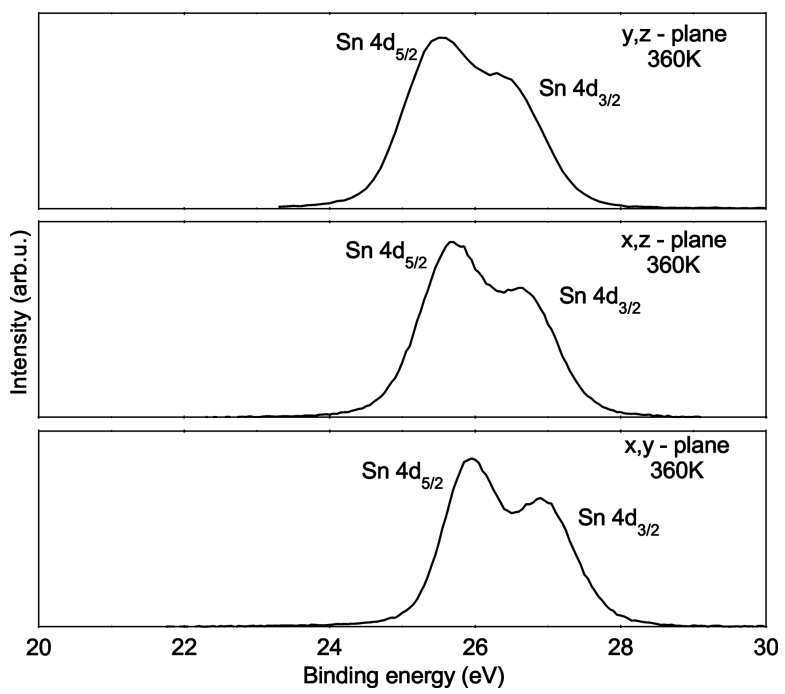

Fig. 10. XPS anisotropy of Sn 4d spin-orbit doublet in PE phase.

lated to Sn atoms in non-polar elementary cells. Such cells are placed in domain walls of the FE phase. Another two higher energy doublets are related to two nonequivalent pairs of $\mathrm{Sn}$ atoms in the FE phase.

Anisotropy of Sn 4d spectra, which were registered from surfaces perpendicular to $z, y$, and $x$ directions, in the PE phase is not so high. This anisotropy could be determined by different properties of near-surface layers. In the FE phase, the anisotropy of XPS is clearly seen. For example, Sn 4d $y$-cut RT spectra could be fitted by two doublets, which are similar to the two higherenergy doublets in the Sn 4d $z$-cut RT spectra. For $y$ cut the low-energy doublet, which is traced from the PE phase, is not seen. But for $x$-cut in the FE phase this low-energy doublet has the highest intensity. The observed difference for the Sn 4d XPS registered from $x-, y$-, and $z$-cuts in the FE phase could be related to the
Table 6. Anisotropy of the line width in FE (RT) and PE $(360 \mathrm{~K})$ phases.

\begin{tabular}{|c|c|c|c|c|c|c|}
\hline \multicolumn{7}{|c|}{ FWHM (eV) } \\
\hline \multirow[t]{2}{*}{ Peak } & \multicolumn{2}{|c|}{$y z$ plane } & \multicolumn{2}{|c|}{$x y$ plane } & \multicolumn{2}{|c|}{$x z$ plane } \\
\hline & RT & $360 \mathrm{~K}$ & RT & $360 \mathrm{~K}$ & RT & $360 \mathrm{~K}$ \\
\hline $\mathrm{P} 2 \mathrm{p}_{3 / 2}$ & 1.0 & 1.1 & 1.0 & 1.0 & 1.1 & 1.1 \\
\hline $\mathrm{P} 2 \mathrm{p}_{1 / 2}$ & 1.0 & 0.9 & 1.0 & 0.9 & 1.1 & 0.9 \\
\hline $\mathrm{S} 2 \mathrm{p}_{3 / 2}$ & 1.1 & 1.1 & 1.0 & 0.9 & 1.2 & 1.3 \\
\hline $\mathrm{S} 2 \mathrm{p}_{1 / 2}$ & 1.0 & 1.1 & 1.1 & 0.9 & 1.3 & 1.4 \\
\hline Sn $3 d_{5 / 2}$ & 1.3 & 1.3 & 1.8 & 1.3 & 1.4 & 1.3 \\
\hline $\operatorname{Sn} 3 d_{3 / 2}$ & 1.3 & 1.3 & 1.7 & 1.3 & 1.3 & 1.4 \\
\hline
\end{tabular}

shape of the domain walls and to their different concentration on crystal surfaces. Also, for the perpendicular to $y$ direction planes (010), with variation of their position, different non-equivalent pairs of $\mathrm{Sn}$ atoms are placed near the surface. For the $z$-cut both types of the Sn non-equivalent atoms simultaneously are located at the surface. Probably this structure peculiarity determines greater difference in the spectral area for the doublets in Sn 4d y-cut RT spectra.

Anisotropy could be a result of different type $\mathrm{Sn}$ ions placed at surface. In FE phase, the macroscopic field of spontaneous polarization also modifies surface properties [3] in different manner for the polar $y z$ and nonpolar planes. On the Sn/Ge (111) surface [13] three components in the line shape of the Sn $4 \mathrm{~d}$ core level also reflect the three inequivalent positions of the $\mathrm{Sn}$ atoms that form the unit cell.

The experimental binding energies and chemical shifts of atoms at different planes in both the FE (RT) and PE $(360 \mathrm{~K})$ phases are given in Table 5. The electronic structure measurements revealed the chemical shifts of Sn and P states to a higher binding energy and shifts of S states to a lower binding energy. This shift suggests a charge transfer from Sn and P to S atoms. However, the binding energies and chemical shifts are crystallographic plane-dependent. Also, they change at the ferroelectric phase transition. In the FE phase, the chemical shifts of $\mathrm{Sn}$ and $\mathrm{P}$ atoms are higher while those of $\mathrm{S}$ atoms are smaller. Due to the non-equivalent positions of the $\mathrm{Sn}$ atoms in FE phase the line width in FE (RT) phase significantly increases (Table 6) mainly in $x y$ plane.

\section{Conclusions}

X-ray photoelectron spectra of the valence band and of the principal core levels of the semiconductor ferroelectric $\mathrm{Sn}_{2} \mathrm{P}_{2} \mathrm{~S}_{6}$ crystal are presented in the energy range from 0 to $1400 \mathrm{eV}$. A molecular model of the 
crystal is used for $a b$ initio theoretical calculations of binding energies. Theoretical values of the binding energies are close to the experimental ones. The structure of valence band is calculated and confirmed experimentally. The XPS studies revealed the crystallographic plane-dependent binding energies and chemical shifts which also change at the ferroelectric phase transition. Appearance of non-equivalent positions of $\mathrm{Sn}$ atoms in FE phase split the spin-orbit doublets of Sn $3 d$ and $4 d$ spectra.

\section{Acknowledgements}

This work was performed with the financial support of the Lithuanian State Science and Studies Foundation and within the framework of the Lithuania-Ukraine project.

\section{References}

[1] J. Grigas, E. Talik, and V. Lazauskas, X-ray photoelectron spectroscopy of $\mathrm{Sb}_{2} \mathrm{~S}_{3}$ crystals, Phase Transitions 75, 323 (2002).

[2] J. Grigas, E. Talik, and V. Lazauskas, X-ray photoelectron spectra and electronic structure of $\mathrm{Bi}_{2} \mathrm{~S}_{3}$ crystals, Phys. Status Solidi B 232, 220 (2002).

[3] J. Grigas, E. Talik, and V. Lazauskas, X-ray photoelectron spectroscopy of ferroelectric semiconductor SbSI crystals, Lithuanian J. Phys. 44, 427 (2004).

[4] J. Grigas, E. Talik, M. Adamiec, V. Lazauskas, and V. Nelkinas, XPS and electronic structure of quasi-one- dimensional BiSI crystals, J. Electron Spectrosc. Related Phenom. 153, 22 (2006).

[5] J. Grigas, E. Talik, M. Adamiec, and V. Lazauskas, $\mathrm{X}$-ray photoelectron spectra and electronic structure of quasi-one-dimensional SbSeI crystals, Cond. Matter Phys. 10, 101 (2007).

[6] Yu.M. Vysochanskii, T. Janssen, R. Currat, R. Folk, J. Banys, J. Grigas, and V. Samulionis, Phase Transitions in Ferroelectric Phosphorous Chalcogenide Crystals (Vilnius University Publishing House, Vilnius, 2006).

[7] J. Grigas, Splitting of the soft mode in a double well potential of SbSI, Ferroelectrics 226, 51 (1999).

[8] K. Kuepper, B. Shneider, V. Caciuc, M. Neumann, A.V. Postnikov, A. Ruediger, A.A. Grabar, and Yu.M. Vysochanskii, Electronic structure of $\mathrm{Sn}_{2} \mathrm{P}_{2} \mathrm{~S}_{6}$, Phys. Rev. B 67, 115101 (2003).

[9] Gaussian Basis Sets for Molecular Calculations, ed. S. Huzinaga (Elsevier, Amsterdam, 1984).

[10] M.W. Schmidt, K.K. Baldrige, J.A. Boatz, et al., General atomic and molecular electronic structure system, J. Comput. Chem. 14, 1347 (1993).

[11] C.J. Pickard and M.C. Payne, Extrapolative approaches to Brillouin-zone integration, Phys. Rev. B 59, 4685 (1999).

[12] K.Z. Rushchanskii, Yu.M. Vysochanskii, and D. Strauch, Ferroelectricity, nonlinear dynamics and relaxation effects in monoclinic $\mathrm{Sn}_{2} \mathrm{P}_{2} \mathrm{~S}_{6}$, Phys. Rev. Lett. 99, 207601 (2007).

[13] A. Tejeda, R. Cortés, J. Lobo-Checa, C. Didiot, B. Kierren, D. Malterre, E.G. Michel, and A. Mascaraque, Structural origin of the $\mathrm{Sn} 4 \mathrm{~d}$ core level line shape in $\mathrm{Sn} \mathrm{Ge}(111)-(3 \times 3)$, Phys. Rev. Lett. 100, 026103 (2008).

\title{
FEROELEKTRINIU $\mathrm{Sn}_{2} \mathrm{P}_{2} \mathrm{~S}_{6}$ KRISTALU RENTGENO FOTOELEKTRONINIAI SPEKTRAI IR ELEKTRONINE SANDARA
}

\author{
J. Grigas $^{\text {a }}$, E. Talik ${ }^{\text {b }}$, V. Lazauskas ${ }^{\text {c }}$, Yu.M. Vysochanskii ${ }^{d}$, R. Yevych ${ }^{\text {d }}$, M. Adamiec ${ }^{\text {b }}$, V. Nelkinas ${ }^{\text {c }}$ \\ ${ }^{a}$ Vilniaus universitetas, Vilnius, Lietuva \\ ${ }^{\mathrm{b}}$ Silezijos universiteto Fizikos institutas, Katovicai, Lenkija \\ ${ }^{\mathrm{c}}$ Vilniaus universiteto Teorinès fizikos ir astronomijos institutas, Vilnius, Lietuva \\ ${ }^{\mathrm{d}}$ Užgorodo universitetas, Užgorodas, Ukraina
}

\begin{abstract}
Santrauka
Rentgeno fotoelektronų spektroskopija ištirtos elektroninès vienašių feroelektrinių $\mathrm{Sn}_{2} \mathrm{P}_{2} \mathrm{~S}_{6}$ monokristalų savybès. Gauti valentinès juostos (VJ) ir svarbiausiu gilių lygmenų paraelektrinės ir feroelektrinès fazių spektrai nuo ìvairių kristalografinių plokštumų. Fotoelektronu sužadinimo šaltinis buvo $\mathrm{Al} \mathrm{K}{ }_{\alpha} 1486,6 \mathrm{eV}$ monochromatinè spinduliuotė. Sužadintų fotoelektronų spektrai matuoti energijos ruože nuo 0 iki $1400 \mathrm{eV}$. Eksperimentiškai gautos fotoelektronų energijos yra palygintos su teorinių $a b$ initio skaičiavimu
\end{abstract}

rezultatais molekuliniam $\mathrm{Sn}_{2} \mathrm{P}_{2} \mathrm{~S}_{6}$ kristalo modeliui. Apskaičiuota ir eksperimentiškai patvirtinta kristalo VJ sandara abiejose fazèse. VJ sudaro penkios juostos, o jų smailès yra nuo 3,3 eV iki 14,5 eV žemiau Fermio lygmens. Ivertinti Sn, S ir I atomų cheminiai poslinkiai. Ištirta feroelektrinio fazinio virsmo įtaka VJ sandarai ir gilių lygmenų spektrams. Nustatyta, kaip fazinis virsmas keičia atomų krūvius, ryšiu stiprius, VJ elektroninę sandarą ir gilių lygmenu juostų pločius bei $\mathrm{Sn}, \mathrm{S}$ ir I atomų cheminius poslinkius, kurie priklauso nuo kristalografinès plokštumos. 